Cornell University Law School Scholarship@Cornell Law: A Digital Repository

\title{
Barriers to Participatory eRulemaking Platform Adoption: Lessons Learned from RegulationRoom
}

\author{
Mary J. Newhart \\ Cornell eRulemaking Initiative, Cornell Law School, mjn3@cornell.edu \\ Joshua D. Brooks \\ Cornell eRulemaking Initiative
}

Follow this and additional works at: http://scholarship.law.cornell.edu/ceri

Part of the Administrative Law Commons, and the Public Affairs, Public Policy and Public Administration Commons

\section{Recommended Citation}

Newhart, Mary J. and Brooks, Joshua D., "Barriers to Participatory eRulemaking Platform Adoption: Lessons Learned from RegulationRoom" (2017). Cornell e-Rulemaking Initiative Publications. 19.

http://scholarship.law.cornell.edu/ceri/19 


\title{
Barriers to Participatory eRulemaking Platform Adoption: \\ Lessons Learned from RegulationRoom
}

\author{
Mary Newhart \\ CeRI (Cornell eRulemaking Initiative) \\ Cornell Law School \\ mjn3@cornell.edu
}

\author{
Joshua Brooks \\ CeRI (Cornell eRulemaking Initiative) \\ Cornell Law School \\ jdb386@cornell.edu
}

\begin{abstract}
Rulemaking, the process through which United States (U.S.) federal government agencies develop major health, safety and economic regulations, was an early target of electronic government (e-government) efforts. Because it was an established decision-making process that had substantial formal requirements of transparency, public participation and responsiveness it seemed a perfect target for technology-supported participatory policymaking. It was believed that new technologies could transform rulemaking, increasing its democratic legitimacy and improving its policy outcomes by broadening the range of participating individuals and groups (Brandon and Carlitz, 2003; Coglianese, 2004; Noveck, 2004). Despite the promise of a more deliberative and democratic process, rulemaking efforts have failed to produce broader meaningful public engagement. In this paper we examine if lack of adoption of participatory eRulemaking platforms can be explained by the disruption to agencies' established rulemaking practices. We will consider how agencies react to technological innovation as a risk due to their deep-rooted organizational cultures and the impact of judicial and political oversight. We will provide examples of agency risk and culture, including from our own experiences with RegulationRoom, a socio-technological participation platform that has facilitated public participation in six federal rulemakings. We will also draw on a comparison of for-profit
\end{abstract}


businesses and rulemaking agencies in thinking about motivation to adopt (or avoid) new technologies.

\section{Introduction}

For decades, rulemaking - the process by which federal agencies make new environmental, consumer protection, financial and other regulations - has included substantial participation rights for stakeholders and members of the general public. However, these participation rights have typically been exercised only by sophisticated insiders such as large regulated corporations and trade associations (Farina, Epstein, Heidt, and Newhart, 2012). Individuals, small businesses and civic organizations directly affected by regulation have been conspicuously absent. Because of this, the rulemaking process has been criticized as a highly technocratic process, where substantive participation comes from only a small number of insidethe-beltway professionals (Noveck, 2015).

Since the late 1990s, the advent of digital technologies have been predicted to change this situation (Brandon and Carlitz, 2003; Coglianese, 2004; Noveck, 2004). However, even the creation of a government-wide eRulemaking portal, Regulations.gov, through which users can view rulemaking proposals and submit comments, has had little effect on broadening effective rulemaking participation. Former U.S. Deputy Chief Technology Officer Beth Simone Noveck (2015) has said that implementing the Open Government vision of collaboration and conversation between government and citizens would "require a radical reinvention of government: fundamentally redesigning, not merely reforming, how institutions make decisions by opening them up to the value embedded in citizens' skills, talents, and abilities."

We have identified elsewhere the design requirements of a system that supports a deliberative, knowledge-building process in rulemaking participation (Farina, Newhart, and 
Blake, 2015; Farina, Newhart and Heidt, 2014; Farina, Epstein, Heidt and Newhart, 2014). This paper explores why government has not adopted technological innovations that would enable and facilitate collaboration and conversation between government and citizens in rulemaking. In thinking about the adoption of such participatory eRulemaking technologies, we will look at how agencies react to technological innovation as a risk. Others have observed that technology innovation can be perceived by government as challenging or even disruptive (Mergel, 2013; Christen and Overdorf, 2000; Rogers, 2003). There have been few attempts to systematically review the risks that influence the adoption and implementation of e-government technologies (Weerakkody, El-Haddadeh, Al-Sobhi, Shareef, and Dwivedi, 2013). Here, we argue that systems that provide opportunities for expanded participation beyond the traditional rulemaking process are potentially disruptive to agencies, and that this perception of risk influences government decisions around adopting participatory eRulemaking systems. We will explore federal agency organizational culture and the impact of judicial and political oversight on agency willingness to take risks with new technologies. Examples are provided to support understanding of agency risk and culture. We draw from our own experiences with Regulation Room, a sociotechnological participation platform that has facilitated public participation in six federal rulemakings. We will also draw on a comparison of for-profit businesses and rulemaking agencies in thinking about motivation to adopt (or avoid) new technologies.

\section{Rulemaking}

\section{A. The Traditional Process}

Rulemaking is one of the U.S. federal government's most important methods of making public policy (Kerwin, 2003). Congress makes laws that are often abstract and delegates policy and technical issues to agencies, who must implement them by providing specific guidelines 
(Muhlberger, Stomer-Galley, and Webb, 2012; Brandon and Carlitz, 2002). In the typical rulemaking, the federal Administrative Procedure Act requires that the originating agency give the public notice of what it is proposing and why. The agency must then allow time, typically 6090 days for important rules, during which any interested individual or entity may comment on the proposal. By law, the agency must consider every comment. If it decides to adopt its proposed regulation, it must demonstrate this consideration in a written statement that responds to relevant questions, criticisms, arguments, and suggestions (Lubbers, 2012). The public record of the rulemaking - including all submitted comments - is used by the courts in settling any challenge that may be brought against the rule.

Although rulemaking's notice and comment process enables anyone to submit a comment, the process is not like a ballot initiative or an up-or-down vote. Decades of judicial elaboration have constructed rulemaking as a process in which outcome legitimacy turns on a formally transparent process of reasoned deliberation (Lubbers, 2012; Kerwin, 2003). Rulemaking is not a plebiscite; hence, mere expressions of outcome preferences hold little value for agencies. Effective commenters create value by articulating legal, factual, and/or policy reasons for their preferred outcomes. An agency is not permitted to base its final rule on the number of comments of those who support over those who oppose it. The final rule's justification must be based on sound reasoning and address trade-offs and opposing views.

\section{B. The Emergence of eRulemaking}

Broadly defined, eRulemaking is the application of information technology to the rulemaking process. The first move towards eRulemaking was in 1994 when the Office of the Federal Register made the Daily Federal Register, the official daily publication for rules, proposed rules, and notices of Federal agencies and organizations, available online. By the start 
of the $21^{\text {st }}$ century, a limited number of agencies had begun building websites containing rulemaking documents, and they were allowing members of the public to submit comments by email (Coglianese, 2004; Lubbers, 2012). A goal of these efforts was to make it easier for members of the public to learn about and participate in the rulemaking process. Rulemaking typically generates a large collection of documents, including proposed rule text, cost benefit analyses and other studies, and the public comments, which are referred to collectively as the rulemaking docket. Prior to online rulemaking, individuals would have to visit an agency's Washington, D.C. headquarters to access these rulemaking materials in the physical docket. First generation e-docketing efforts included the Federal Communications Commission, the Nuclear Regulatory Commission, the Department of Agriculture's National Organic Program, and the Department of Transportation, which had one of the most extensive systems and was the first agency to move its entire rulemaking docket system online in 1998 (Gormley and Balla, 2013).

Proponents believed that e-dockets would allow for more transparency, participation, and informed dialogue. They advocated creating moderated discussions and allowing the threading of comments (Brandon and Carlitz, 2002; Coleman and Gotze 2001). At the same time, however, there were warnings of the downside to increasing public participation, for it would require agencies to read and react to a higher volume of comments, particularly in controversial rulemakings. Some argued that the model of careful individual consideration of each comment would be impossible, that agencies would be pressured to treat comments as a "running tally with the grossest sort of division - basically for or against" (Herz, 2004).

The E-Government Act of 2002 required agencies to accept electronic submissions "to the extent practicable" in rulemaking and to create "an internet-accessible rulemaking docket that includes all public comments and other materials that by agency rule or practice are included in 
the agency docket." The Environmental Protection Agency (EPA) led the federal eRulemaking Initiative, which launched a government-wide web portal, Regulations.gov, to facilitate electronic filing of public comments on proposed regulations. The allied Federal Docket Management System (FDMS) provided agencies the ability to keep rulemaking materials in digital form in e-dockets that could be accessed by the public (Lubbers, 2012). By presidential order, most rulemaking agencies were required to use this new central eRulemaking system; agencies that had been proactive in developing their own systems were required to abandon those systems and migrate to FDMS (OMB, 2012). The head of the inter-agency eRulemaking team responsible for building FDMS described the difficulties in trying to implement the Initiative, "The serious problems that we encountered trying to implement this initiative really rested on a pretty common characteristic - the government cultural insensitivity and sometimes frustrating and impenetrable agency-specific business processes" (Morales, 2003).

Despite considerable agency resistance, the combined force of the E-Government Act and the determination of the Bush Administration, produced a centralized federal eRulemaking system used by all but a handful of rulemaking agencies. Comments could now be filed digitally, rulemaking documents could be accessed online rather than an in-person visit to a docket room. What did not occur in the creation of Regulations.gov and FDMS was a more participatory eRulemaking system that supports deliberation and knowledge-building. Suggestions that had been made for deliberative dialogues and online discussions among commenters were not included (Lubbers, 2012). While technological advances can move rapidly, legal developments move far more slowly. There were many issues around eRulemaking that concerned agency lawyers and administrators. For example, interpretations of the Paperwork Reduction Act and the Privacy Act often make it impossible for agencies to collect demographic data and interest group 
affiliations from the public. Agencies have also struggled with merging blogs, twitter and other social networks with the traditional rulemaking process (Lubbers, 2012). Some agencies, including the Department of Transportation (DOT), consider contact during the comment period to be problematic under internal ex parte contact polices (Farina et al., 2011). Therefore, direct access to rulewriting personnel is forbidden, or severely constrained, from the time the comment period opens until the work on the rule has been finalized.

\section{The Obama Administration Open Government Initiative}

It was hoped that President Obama's Memorandum on Transparency and Open Government would result in a new generation of online rulemaking by providing agencies with guidance and direction on how to implement and best use new technologies. The Memorandum directed Executive agencies to use Web 2.0 and other information technologies to increase transparency, participation, and collaboration in their decision-making (Transparency and Open Government, 2009). Specific direction was given for rulemaking, with Obama's Executive Order 13563 requiring agencies to "afford the public a meaningful opportunity to comment through the Internet on any proposed regulation, with a comment period that should generally consist of not less than 60 days." The Executive Order also requires an "open exchange" of information among government officials, experts, stakeholders, and the public. As part of the Obama Open Government Initiative, possible enhancements were suggested for Regulations.gov to improve navigation, search and layout, to upgrade underlying technology to improve the user interface, and to expand the use of Web 2.0 tools (Hunt, 2010).

As the one-stop portal for citizens to review regulations open for comment and to submit their comments electronically, Regulatons.gov initially led to optimism for Open Government goals. It was believed it could make the rulemaking process more inclusive in scope and more 
open to public discussion (Carlitz and Gunn, 2005). Experience has shown this optimism was misplaced. What Regulations.gov has provided, access to documents and the ability to input comments, is similar to most Open Government initiatives whose primary emphasis and implementation have been on transparency (Lukensmeyer, Goldman, and Stern, 2011). The initial hope that moving the public comment process online would increase meaningful citizen participation has not come to pass (Mulberger et al., 2012).

\section{Rulemaking Innovation}

The rulemaking process is an example of an established governance system that has encountered tensions between adapting to the demand for more participatory practices and working within "well-define and strictly applied rules, polices and organizational hierarchies" (Janssen \& van der Voort, 2016). As a way to overcome these tensions, agencies developed collaborations with academic and civil society researchers. Our own project, RegulationRoom, was initially a collaboration with DOT and CeRI (Cornell eRulemaking Initiative) that worked well because: (1) the agency leadership was strongly committed to using information technology to improve rulemaking; and (2) CeRI researchers were committed to developing systems and practices that would produce broader public engagement that the agency found useful in its rulemaking decisions (Farina et al. 2011). The types of comments that are of value to an agency in a rulemaking - ones with relevant information and sound reasoning, that address trade-offs and opposing views - can be encouraged through the use of deliberation platforms, such as RegulationRoom, that seeks crowdsourced argumentation and deliberation, where the participants are asked to deliberate by exchanging arguments about a selected topic (Aitamurto and Chen, 2017). This is a form of participation that reflects a view of democracy anchored in conceptions of accountability and discussion (Chambers, 2003), infuses transparency to 
government (Aitamurto \& Chen, 2017), and at least potentially generates legitimacy (Richards and Gastil 2015).

\section{A. The RegulationRoom Project}

RegulationRoom is an experimental platform for public participation in government rulemaking processes created by a cross-disciplinary group of Cornell researchers. CeRI used selected live U.S. federal rulemakings to experiment with human and computer support for public engagement and discussion. The ultimate goal of RegulationRoom was to provide guidance on design, technological, and human intervention strategies - grounded in theory and tested in practice - for effective eRulemaking systems.

CeRI researchers have developed expertise in: (1) using conventional and social media to alert and engage people who never before participated in rulemaking processes; (2) translating long, complicated government proposals into a concise and understandable online format; (3) educating people about rulemaking and other public policymaking processes; and (4) mentoring new participants in making comments that convey relevant knowledge and informed views.

RegulationRoom is purposefully designed to include elements that can make public policymaking more transparent, participatory, and collaborative. The design signals the importance of commenters' learning about, and engaging with, the substance of the agency's proposal. Rather than the conventional blog format of a column of text, below which the comment stream gradually develops, RegulationRoom topic pages are organized in a side-byside, two-column format. Because of the length and complexity of typical rulemaking documents, the content is triaged for importance and translated into comprehensible language. This work was done manually by the CeRI team, as summarization and translating technologies, 
as of yet, cannot accomplish this automatically. Several strategies are used to layer information. Content is organized into manageable, discrete topics and subtopics that make sense to the target stakeholder groups. A navigation carousel and drop-down menus give an easy overview of the discussion's scope and allows participants to find the issues most meaningful to them. Glossaries are also utilized to assist participants with acronyms and words or phrases with technical meaning. To provide greater information depth for participants who wish to see the original agency documents, each subsection contains hyperlinks to the relevant portion of the primary rulemaking materials. The RegulationRoom participatory environment models the kind of engagement valuable in rulemaking and provides support for participants at whatever level of participatory skill they bring into the discussion. The side-by-side format continually reinforces the importance of acquiring information about the agency proposal, while the segmented topic and subtopic structure facilitates understanding the issues. Voting and ranking tools do not play a prominent role, to signal the deliberative rather than the aggregative nature of rulemaking. Participants may endorse another comment, but no tally of the number of endorsements is displayed.

Human facilitative moderation supports participants in effective commenting. Helping participants to acquire the deliberative skills of giving reasons, substantiating claims, and acknowledging competing interests. The moderators were typically students in the e-Government Clinic at the Cornell Law School. They received training in conflict resolution, group facilitation techniques, and on the substantive content of the agency proposal. They moderated the discussions according to a detailed protocol, with active monitoring and feedback from senior CeRI researchers with conflict resolution and substantive content expertise. A specially designed moderator interface facilitated workflow among moderators and kept track of moderation in 
progress. Moderators assisted participants in identifying relevant knowledge and experience, clearly articulating their concerns and interests, and explaining their outcome preferences. Where needed, moderators would correct misconceptions about the proposal and point commenters to relevant information. Because moderator response to individual commenters occurs within the publicly visible comment stream, these interactions guide and model effective participation skills for other participants.

\section{B. Outcomes}

In over six years of hosting online public commenting the platform was successful in utilizing strategies to support crowdsourced argumentation and deliberation to achieve informed, inclusive and insightful participation. That real world testing primarily involved participants with no prior experience in such policy processes (65\%-95\% self-reported newcomers). Even on complex and controversial questions, online discussion was thoughtful, informative, candid and civil.

During the course of the project, the RegulationRoom team partnered with the DOT and the Consumer Financial Protection Bureau (CFPB) to offer six live federal rulemakings. These rulemakings received approximately 2500 comments by over 750 individual users on the RegulationRoom platform (see Table 1). Even on complex and controversial questions - such as the accessibility standards for websites selling air travel, the extent to which mortgage holders should be required to assist borrowers in trouble, or the restrictions that should be placed on "robo-calls" in debt collection from consumers - the discussion on RegulationRoom was thoughtful, informative, candid and remarkably civil. 
The project was lauded as a success by the heads of both partnering federal agencies.

CFPB Director Richard Cordray (2014) described it as "producing a level of engagement that deepens the knowledge on both sides, and allows citizens to actually participate in the rulemaking process by means of a controlled forum." Secretary of Transportation Ray LaHood (2010) called the project "a groundbreaking partnership with Cornell University to make commenting on this proposed rule easier and more transparent. With its interactivity, the Regulation Room is even more accessible and dynamic than regulations.gov" (LaHood, 2010). In both private meetings with the researchers and in public panel discussions about rulemaking innovation, agency rulemaking staff responded positively, agreeing that the RegulationRoom discussion involved stakeholders with useful information to contribute who did not usually participate effectively in the rulemaking process. The White House awarded DOT a Leading EGovernment Practices Award for the RegulationRoom collaboration. Finally, users of the platform responded positively to surveys about their experience. This feedback included thanking the project for giving them a voice, for responding to their comments, and for giving them hope.

However, despite the accolades and the accomplishments of the project, the RegulationRoom technology and know-how has not been adopted by U.S. federal agencies. ${ }^{1}$ The next section examines possible explanations for this.

\section{Innovation as Disruption}

\section{A. Overview}

\footnotetext{
${ }^{1}$ The technology, an Open Source e-participation platform based on Drupal, is available for download on Github and as a Drupal Distribution. A Sandbox Environment (http://sandbox.smartparticipation.com/) allows potential users to learn more about the about the structure and functionalities of the platform, get some advice from the designers, and actually practice setting up a discussion.
} 
Rulemaking agencies are mission-oriented agencies (Belsey and Ghatak 2003). We argue that their organizational culture and institutional backdrop are barriers to the adoption of technologies, like RegulationRoom, that inject new and innovative forms of public participation into their established processes. As discussed by Janssen and van der Voort (2016), "governments and large organizations try to manage the new developments using established mechanisms of governance, with stability and accountability as the main values. However, these mechanisms were largely not developed to adapt to changes."

Also, as noted by Jennifer Nou (2008), the twin goals of rulemaking - technocratic and democratic - often appear to be at loggerheads. The rulemaking agency must strike a balance between the appropriate "limits of bureaucratic discretion amidst competing demands of expertise and public participation" (Nou, 2008). Traditional rulemaking processes favor sophisticated and experienced stakeholders (industry, trade associations and national advocacy groups) who routinely follow and interact with agency policymakers through communications that include filing lengthy formal responses when public comment is requested (Farina et al., 2012; Kerwin, 2003). By contrast, based on the experience of RegulationRoom, participation from eRulemaking platforms comes largely from novice commenters who are inexperienced in norms and practices of rulemaking. Experienced stakeholders may observe the participation that occurs on a site such as RegulationRoom, but these stakeholders have no incentive to change conventional participation practices that have proved effective. ${ }^{2}$ An influx of novice participants - whose forms of argumentation and claim substantiation tend to differ from those of

\footnotetext{
${ }^{2}$ Sophisticated, experienced commenters use the official government portal, Regulations.gov, to submit their comments in the form of multi-page PDF attachments. By intentional design, that kind of participation was not possible on RegulationRoom which did not permit attachments as a substitute for responsive, interactive discussion with other participants.
} 
experienced rulemaking insiders" (Farina et al., 2012) - at least shifts, if not actually upsets, the balancing act the rulemaking agency is trying to maintain.

Agencies are typically given rulemaking authority as part of a legislative mandate to solve complex problems with strongly conflicting interests and trade-offs with other important societal values. Congress, for example, has defined the mission of the Federal Reserve System as "providing the nation with a safer, more flexible, and more stable monetary and financial system" (Federal Reserve, 2013). The EPA describes its mission as “protecting human health and the environment" (EPA, 2014) - a mission that often (at least apparently) collides with objectives such as economic growth and job creation. The complexity of the problems they are required to tackle makes agencies vulnerable to reversal during the court challenges that are almost inevitable in important rulemakings. The cross-cutting interests and conflicting societal values affected by their decisions make agencies vulnerable to very public criticism by their Congressional and White House overseers. Hence, the external environment of judicial and political oversight raises the stakes as agencies try to balance reliance on their own expertise with attending to input from those who file comments. Innovations that disrupt the conventional rulemaking process introduce unknown variables that may bring about institutional consequences from the judiciary and legislature.

We argue that rulemaking agencies have a disposition of risk averseness to use innovative, potentially disruptive technologies, such as systems that encourage and facilitate broader public engagement in the rulemaking process. In part, this risk averseness is inherent and reflexive; in part, it is deliberate and reasoned. We explore each of these dimensions in turn.

\section{B. Agency Culture}


The Bush Administration eRulemaking Initiative that produced the federal rulemaking portal Regulations.gov was one element of an ambitious broader plan, the President's Management Agenda. This major, multi-faceted administrative reform initiative aimed to make the federal government more "citizen-centric, market-based, and results-oriented" (President's Management Agenda, 2002). In essence, the goal was to reorient federal agency behavior according to the principles, practices, and metrics of private corporations.

Within that framework, the emphasis on adopting innovative technologies (including eRulemaking) made sense. The dictates of the marketplace require that businesses, from their very beginning, offer something new or improved. Whether it be bringing a new product to the marketplace (e.g., Xerox), providing lower cost alternative goods through creative manufacturing (e.g., Ford Motors at the beginning of the $20^{\text {th }}$ century), or creating demand for a new service (e.g., Uber), the organizational culture of the private corporation is predisposed to embrace innovation, for without innovation the enterprise will not succeed initially and cannot sustain success (Downes and Nunes, 2013).

However, government agencies have an organizational culture fundamentally different from that of the private corporation. This difference is rooted in a fundamentally different origin story. Private corporations are created to earn a profit. The Harvard Business School, which consistently ranks at the top of MBA programs with alumnae as Fortune 500 CEOs, is credited with honing the philosophy that for-profit corporations exist to make money for shareholders (McDonald, 2017; Stewart, 2017). To be sure, this single-minded conception of the corporate mission has been challenged (McDonald, 2017; Stewart, 2017). Still, even when businesses are supposedly created out of a founder's intellectual interest in or passion for a specific industry (e.g., Apple) or some extra-business goal (e.g., job creation, as with Shinola Watches out of 
Detroit), sustained profitability is the desideratum of survival. And, as Apple epitomizes, innovation is the engine of profitability (Christensen and Allworth, 2011). By contrast, regulatory agencies are created to solve problems that, if left unchecked, will disrupt a segment of industry or society and cause harm. These problems - reducing pollution in the air, water and soil; preventing the marketing of adulterated food or unsafe drugs; reducing deaths from traffic accidents; remediating unsafe mines and other workplaces; regulating the financial markets to prevent fraud and other harmful practices without dampening beneficial entrepreneurial behavior - tend to be complex to the point of often qualifying as "wicked" problems. ${ }^{3}$ They tend to involve multiple variables, including strongly conflicting stakeholder interests (e.g., environmentalists vs. mining industry) and trade-offs between important societal values (e.g., addressing global warming by cutting carbon pollution vs. loss of jobs in fossil fuel industry). Every variable adds an element of complexity, and each variable itself, then, is a problem needing a solution - how to fit the individual variable into the whole without upsetting the delicate balance necessary to achieve its regulatory mission.

The result is a fundamentally different organizational orientation toward risk (Besley and Ghatak, 2003; Bozeman, 2002). For-profit corporations have a culture of risk capitalization: Continually seeking both greater efficiencies of operation and innovations that increase the market share of their products or services, they are predisposed towards openness to new, even disruptive, technologies (Downes and Nunes, 2013). Risk-taking is necessary to achieve the organizational purpose of increasing shareholder profits (Kose, Lubomir, and Yeung, 2008). Regulatory agencies have a culture of risk mitigation (Workman, 2015; Davidson, 2014). Not

\footnotetext{
${ }^{3}$ A wicked problem is on that is difficult, even impossible, to solve because of incomplete, contradictory, and evolving information and needs.
} 
only are their missions far more complex, but the metrics, and even the meaning, of success are far more contestable. Innovation - particularly innovation that disrupts the status quo represents not an opportunity to be capitalized upon, but rather a demand on scarce resources and another problem to be managed (Workman, 2015; Davidson, 2014).

An example of how this cultural predisposition impedes successful implementation of new technology comes from Barry Bozeman's case study (Bozeman, 2002) of a major technology initiative of the Internal Revenue Service: the Tax Systems Modernization (TSM) program undertaken in the late 1980s and early 1990s. The need for a largescale update of the IRS's tax systems technology was uncontested and compelling. Yet, the TSM program was largely a failed enterprise (Bozeman, 2002; Vann, 2011). Bozeman concluded that a principal cause of failure was an organizational culture of extreme risk-averseness. Of course, it is possible that the IRS culture was idiosyncratic, but this was not the experience of a consultant interviewed by Bozeman, who had worked on IT projects in other federal agencies. This consultant compared his experience at the Federal Aviation Administration (FAA), which undertook a comparably large technological overhaul of a "mission critical" system: "At FAA the culture was so risk averse that it was better to do nothing except what is safe. Operations were too risky." (Bozeman, 2002).

As noted earlier, those charged with implementing the Bush Administration eRulemaking Initiative struggled against entrenched aspects of agency culture (Morales, 2003). This struggle persisted over the years of development and implementation (Committee on the Status and Future of Federal eRulemaking, 2008), even though the President had ordered agencies to participate. The resulting Regulations.gov system digitized the existing rulemaking process rather than working any significant process change. This suggests how difficult it will be to 
persuade agencies to adopt the new technology of public participation systems that enable a broader range of participants to take part in rulemaking. Because agencies' current practices meet their notice-and-comment responsibilities, there is no external compulsion for change. Moreover, by bringing new voices into the process - voices that represent different interests and have different modes of participation than experienced commenters (Epstein, Farina, and Heidt, 2014) - public participation systems like RegulationRoom introduce potentially disruptive new variables into the established rulemaking process.

\section{Institutional Context}

Relationships with other institutions of government - especially the judiciary and Congress - amplify rulemaking agencies' disposition to avoid risk. Rulemaking is a long and resource-intensive process. EPA, one of the most prolific federal rulemakers, estimates a 3-5 year timeline for a major rule (Kerwin, 2003). Virtually all major rules are challenged in court by an interest that is affected by the new regulation; indeed, it is not uncommon for the agency to be challenged simultaneously by one side for doing too much and by the other side for doing too little. A significant portion of these judicial challenges result in invalidating, or at least delaying, at least a portion of the new regulation. Even though the agency will often be able to remediate the problem perceived by the court, and implement the same or substantially the same regulation as the agency originally preferred, a court loss imposes heavy resource and public relations costs. Moreover, it defers implementation of the solution that the agency believes is required by its regulatory mandate.

The perils of innovation are illustrated by a DOT rulemaking on airline passenger rights in which RegulationRoom had been used to increase the participation of airline travelers. The Secretary of Transportation himself had urged consumers to use the platform in the news 
conference announcing initiation of the public comment period (LaHood, 2010). Response was strong, particularly after a Washington Post travel article highlighted the rulemaking and availability of the platform (Elliott, 2010). The regulation DOT ultimately adopted was opposed by numerous airlines, one of which argued to the reviewing court that the use of RegulationRoom tainted the proceeding and was grounds for invalidating the regulation (Spirit v. U.S.D.O.T., 2012). The challenge was not successful, but the court resolved the issue on grounds that did not preclude similar challenges in the future. ${ }^{4}$

The judiciary is only one external threat to rulemaking agencies. Agencies have oversight relationships with the Senate (which must confirm agency leadership nominated by the President) and with the House (in which appropriations bills originate). A powerful rulemaking agency like EPA, whose regulatory mandate stretches across geographic regions and industrial sectors, may be subject to oversight by more than two dozen House and Senate committees and subcommittees. Any one of those committees may summon agency leadership to a hearing in which members of Congress berate the agency for hours before news media and anyone watching C-SPAN (C-SPAN, 2013). What Congress perceives as a regulatory misstep can cost the agency dearly in terms of leadership turnover and budgetary sanctions.

Recent events have underscored that technology can provide a "neutral" stalking horse for attacking an agency that is implementing a substantively controversial regulatory program. In April 2014, Secretary of Health and Human Services Kathleen Sebelius resigned in the wake of what was perceived as a disastrous performance in congressional hearings on the problems with the rollout of HealthCare.gov (Shear, 2014). In an example even closer to the subject of

\footnotetext{
${ }^{4}$ The court determined that DOT's written justification for the rule did not rely on anything from RegulationRoom commenters that could not be found somewhere else in the rulemaking record. Therefore, the court did not need to rule on the permissibility of DOT's innovative public engagement pilot.
} 
this paper, EPA encountered a political firestorm over its use of social media in the 2014 Clean Water Rule rulemaking (Lipton and Shear, 2015). This new regulation proposed to redefine the meaning of the term "waters of the United States," which is the Clean Water Act's method of describing the bodies of water EPA may regulate (Definition of "Waters of the United States," 2014). The proposed definition broadened EPA's jurisdiction and was sharply opposed by, among others interests, the powerful agricultural lobby, and the rulemaking had come to the attention of many members of Congress. EPA has been one of the most proactive agencies in incorporating social media tools into its regulatory processes. In the Waters of the U.S. rulemaking it used, for the first time, an app called Thunderclap (Lipton \& Shear, 2015). Selfdescribed as "the first-ever crowdspeaking platform" and by others as "an online flash mob," Thunderclap allows large groups of people to share a single message at once (Thunderclap; Lipton and Shear, 2015). EPA's Thunderclap message was: “Clean water is important to me. I support E.P.A.'s efforts to protect it for my health, my family and my community." (Lipton and Shear, 2015.). Even before EPA's final decision on the rulemaking in August 2015, opponents were outraged (Lipton and Shear, 2015). The Senate Committee on Environment and Public Works requested an opinion on the legality of EPA's conduct from the Government Accountability Office, an independent agency that works for Congress and is often referred to as its watchdog. GAO's December 2015 finding lambasted the agency: "EPA's use of Thunderclap constituted covert propaganda, in violation of the publicity or propaganda prohibition," a law ${ }^{5}$ that prohibits agencies from using appropriations for unauthorized publicity or propaganda purposes (Lipton and Davenport 2015; GAO, 2015).

\footnotetext{
${ }^{5}$ Section 718 of the Financial Services and General Government Appropriations Act of 2014. Pub. L. No. 113-76, div. E, title VII, Section 718, 128 Stat. 5, 234
} 
The Thunderclap incident continues to haunt EPA. In October 2016, the House Committee on Oversight and Government Reform issued a report concluding, on the basis of the GAO ruling, that "the EPA funded an improper grassroots lobbying effort" (Committee on Oversight and Government Reform, 2016). More broadly, the 2017 Regulatory Accountability Act, which has passed in the House, provides: "After notice or advance notice of a proposed rulemaking, the agency making the rule is prohibited from: (1) advocating for the submission of information to form part of the record of review, (2) appealing to the public to undertake advocacy, or (3) communicating for publicity or propaganda within the United States in a manner not authorized by Congress" (Regulatory Accountability Act, 2017).

Given these highly publicized examples, a rulemaking agency's wariness of technological innovation in the rulemaking process is hardly unreasonable. Adopting technologies that inject more, and different, kinds of public participation into the process will predictably make the agency's task more onerous, for the participation of new voices can be expected to introduce facts, perspectives, and concerns different than those of the existing players. Moreover, process innovation is perilous because it multiplies the possible bases on which the final rule can be attacked in the judicial arena, and it can provide the agency's political overseers with an ostensibly substance-neutral basis on which to attack a controversial regulatory program.

In sum, for rulemaking agencies, adopting socio-technological systems that alter the rulemaking process is tantamount to creating a problem (e.g., more work, more resources, unknown impact on judicial review, potential for political fallout) to solve a problem (a lack of broad-scale public participation) that really does not exist from the perspective of fulfilling the agency's legal responsibilities in notice-and-comment rulemaking. Altering the established 
rulemaking system by adding more public participation is a risky endeavor that has little potential for reward.

\section{Conclusions and Future Study}

Our experience with RegulationRoom has shown that achieving adoption of participatory eRulemaking platforms depends far less on technology than on overcoming the culture of risk adverseness in rulemaking agencies. During the course of our research, we have encountered members of agency rulemaking teams who are highly skeptical of (if not openly hostile to) the idea of more public participation. They associate more public participation — and, in particular, more online participation — with mass e-mail campaigns and similar high-volume/low-value comments. Rulewriters have had to manage this material, along with all the other information generated in the rulemaking, often under time pressure and almost always without additional resources.

We suggest future research needs to focus on how to overcome not only the practical legal and resource barriers, but in how to change the culture in agencies to value and accept the new form of broader rulemaking participation. If agencies, however, are unable to overcome ingrained cultural values and tendencies detrimental to new, better, and broader participation, then perhaps future research should also focus on how to leverage agencies' current organizational culture. That is, future research could work on how to make agencies believe that new forms of public participation are a necessary tool to mitigate a bigger, scarier problem—an underrepresented populace leading to government inefficiency.

\section{Acknowledgements:}

This material is based upon work supported by the National Science Foundation under Grants No. IIS-1314778. Any opinions, findings, and conclusions or recommendations expressed in this 
material are those of the author(s) and do not necessarily reflect the views of the National Science Foundation.

\section{References:}

Aitamurto, T. \& Chen, K. (2017). The value of crowdsourcing in public policy-making: Epistemic, democratic and economic value. Journal of Theory and Practice of Legislation, 5(1), 55-72.

Besley, T. \& Ghatak, M. (2003). Incentives, choice, and accountability in the provision of public services. Oxford Review of Economic Policy, 19(2), 235-249.

Bozeman, B. (2002). Public-value failure: When efficient markets may not do. Public Administration Review, 62(2), 145-161.

Brandon, B. \& Carlitz, R. (2002). Online rulemaking and other tools for strengthening our civil Infrastructure. Administrative Law Review, 54(4), 1421-1478.

Carlitz, R. \& Gunn, R. (2005). E-Rulemaking: A new avenue for public engagement. Journal of Public Deliberation, 1(2).

Carver, T N. (1901). The Risk Theory of Profits. The Quarterly Journal of Economics, 15(3), $456-458$.

Chambers, S. (2003). Deliberative democratic theory. Annual Review of Political Science, 6, 307-206.

Christensen, C. \& Allworth, J. (2011, August 29). Jobs Made Apple Great by Ignoring Profit. Reuters. Retrieved from http://blogs.reuters.com/great-debate/2011/08/29/jobs-made-applegreat-by-ignoring-profit/

Clean Water Rule: Definition of “'Waters of the United States,' 80 Fed. Reg. 37054 (June 29, 2015) (to be codified at 40 C.F.R. pts. 110, 112, 116, 117, 122, 230, 232, 300, 302, \& 401).

Davidson, J. (2014, Jan. 23). Federal Senior Executives Growing Weary and Risk Averse, Says Employee Association. Washington Post, Retrieved from https:/www.washingtonpost.com/

Definition of "Waters of the United States"' Under the Clean Water Act, 79 Fed Reg. 22188 (proposed April 21, 2014) (to be codified at 40 C.F.R. pts. 110, 112, 116, 117, 122, 230, 232, 300, 302, \& 401).

Elliott, C. (2014, April 3). Airline Passengers Get a Chance to be heard on Proposed Regulations. Washington Post. Retrieved from https://www.washingtonpost.com/

Cordray, R. (2014). Prepared Remarks of CFPB Director Richard Cordray at the American Bar Association, April 3, 2014. Retrieved from https://www.consumerfinance.gov/aboutus/newsroom/prepared-remarks-of-cfpb-director-richard-cordray-at-the-american-barassociation/ 
Christensen, C.M. \& Overdorf, M. (2000). "Meeting the Challenge of Disruptive Change." Harvard Business Review, 78(2). 66-76.

Coglianese, C. (2004). "E-Rulemaking: Information technology and the regulatory process" (2004). Administrative Law Review 56(2), 353-402.

Coleman, S. \& Gotze, J. (2001). Bowling together: Online public engagement in policy deliberation. London: Hansard Society.

C-SPAN. (2013, Oct. 9). Sen. Harkin Berating HHS Sec. Kathleen Sebelius on Funding Programs. Retrieved from https://www.c-span.org/video/?c4467987/sen-harkin-beratinghhs-sec-kathleen-sebelius-funding-programs

Downes, L. \& Nunes, P. (2013). “Big-Bang Disruption.” Harvard Business Review, 91(3), 4456.

E-Government Act of 2002, Pub. L. No. 107-347, §206, 116 Stat. 2899, 2915-16.

Epstein, D., Farina, C. \& Heidt, J. (2014). The value of words: narrative as evidence in policymaking. Evidence \& Policy. 10(2), 243-258.

Exec. Order No. 13563, 3 C.F.R. page 215 (2012).

Farina, C., Epstein, D., Heidt, J., \&Newhart, M. (2014). Designing an online civic engagement platform: Balancing "more" vs. "better" participation in complex public policymaking. International Journal of E-Politics, 5(1) 16-40.

Farina, C. R., Epstein, D., Heidt, J. \& Newhart, M. J. (2012). Knowledge in the people: Rethinking "value" in public rulemaking participation. Wake Forest Law Review, 47(5), $1185-1241$.

Farina, C. R., Miller, P., Newhart, M. J., Cardie, C., Cosley, D., \& Vernon, R. (2011). Rulemaking in 140 characters or less: Social networking and public participation in rulemaking. Pace Law Review, 31(1), 382-463.

Farina, C. R., Newhart, M.J., \& Blake, C. (2015). The problem with words: Plain language and public participation in rulemaking. The George Washington Law Review 83(4-5), 1358-1365.

Farina, C., Newhart, M. \& Heidt, J. (2014). Rulemaking vs. Democracy: Judging and Nudging Public Participation That Counts. Michigan Journal of Environmental \& Administrative Law, 2(1), 123-171.

Gormley, W.T., Jr. \& Balla, S. J. (2013). Bureaucracy and Democracy: Accountability and Performance ( $3^{\text {rd }}$ ed.), Sage: Washington, DC.

Janssen, M. \& van der Voort, H. (2016). Adaptive governance: Towards a stable, accountable and responsive government." Government Information Quarterly, 33(1), 1-5.

Herz, M. (2004). Rulemaking. In Developments in Administrative Law and Regulatory Practice 2002-2003, ed. by J. Lubbers, 129-157. Chicago: American Bar Association. 
Hunt, A.T. (2010). eRulemaking: Promoting transparency and participation in the U.S. Presented at the Regulatory Policy at the Crossroads: Towards a New Policy Agenda, OECD, Paris, France, October 28, 2010.

Kose, J., Lubomir, L., \& Yeung, B. (2008). Corporate Governance and Risk-Taking. The Journal of Finance 63(4), 1679-1680.

Kerwin, C.M. (2003). Rulemaking: How government agencies write law and make policy $\left(3^{\text {rd }}\right.$ ed.). Washington, DC: 2003.

LaHood, R. (2010, June 2). More Consumer Protections on Tap for Air Travelers [Blog post]. FAST LANE: The Official Blog of the U.S. Secretary of Transportation. Retrieved from http://usdotblog.typepad.com/secretarysblog/2010/06/more-consumer-protections-on-tap-forair-travelers.html\#.WRHEFty1taQ

Lipton, E. \& Davenport, C. (2015, May 18). Critics Hear E.P.A.'s Voice in Public Comments. New York Times. Retrieved from https://www.nytimes.com.

Lipton, E. \& Shear, M. (2015, December 15). E.P.A. Broke Law with Social Media Push for Water Rule, Auditor Finds. New York Times. Retrieved from https://www.nytimes.com.

Lubbers, J.S. (2012). A guide to federal agency rulemaking $\left(5^{\text {th }}\right.$ ed). Chicago, IL; American Bar Association.

Lukensmeyer, C.J., Goldman, J.P., \& Stern, D. (2011). Assessing public participation in an open government era: A review of federal agency plans. Washington, DC: IBM Center for the Business of Government.

McDonald, D. (2017). The Golden Passport: Harvard Business School, the Limits of Capitalism, and the Moral Failure of the MBA Elites. New York, NY: Harper Collin, 1-20.

Morales, O. (2003). eRulemaking initiative: Trials and tribulations of a frustrated bureaucrat or the proof is in the details." Paper presented at the John F. Kennedy School of Government, Harvard University, January 21-22, 2003.

Mergel, I. (2013). "Social media adoption and resulting tactics in the U.S. federal government." Government Information Quarterly, 30(2), 123-130.

Muhlberger, P., Stromer-Galley, J. \& Webb, N. (2012). An experiment in eRulemaking with natural language processing and democratic deliberation." In Citizen 2.0: Public and Governmental Interaction Through Web 2.0 Technologies, eds. Kathryn Kloby and Maria J. D’Agostino. Hershey, PA: IGI Global Publishers, pp. 23-40.

Noveck, B.S. (2004). The Electronic Evolution in Rulemaking. Emory Law Journal 53(2), pp. 433-522.

Noveck, B.S. (2015). Smart Citizens, Smarter State: The Technologies of Expertise and the Future of Governing. Cambridge, MA: Harvard University Press. 
Office of Management and Budget (2012, August 24). Managing Government Records Directive. (M-12-18). Retrieved from https://www.archives.gov/files/records-mgmt/m-1218.pdf

President's Management Agenda. Executive Office of the President, Office of Management and Budget. Washington, D.C.: Government Printing Office. Retrieved from https://www.acquisition.gov/seven_steps/library/OMBpres-mgmt-agenda2002.pdf

Purchia, L. (2015, May 18). The importance of education and outreach [Blog Post]. The EPA Blog, retrieved from https://blog.epa.gov/blog/tag/communications/

Regulatory Accountability Act of 2017. H.R.5. 115 ${ }^{\text {th }}$ Congress (2017-2018).

Richards, R.C., Jr \& Gastil, J. (2015). Symbolic-cognitive proceduralism: A model of deliberative legitimacy. Journal of Public Deliberation, 11(2).

Roger, E.M. (2005). Adoption of innovation. The Free Press: NY.

Shear, Michael D. (2014, April 10). Sebelius Resigns after Troubles over Health Site. New York Times. Retrieved from https://www.nytimes.com.

Stewart, J.B. (2017, April 24). How Harvard Business School Has Reshaped American Capitalism. New York Times. Retrieved from https://www.nytimes.com.

Spirit Airlines v. U.S.D.O.T. (2012). Petition for Review of Final Rules of the U.S. Department of Transportation. United States Court of Appeals for the District of Columbia Circuit, pp. 78. Retrieved from https://www.cadc.uscourts.gov/internet/opinions.nsf/B3C8FBE2AB1F6A9185257A45004EE 709/\$file/11-1219-1385164.pdf

Thunderclap. (Last visited May 9, 2017). What is Thunderclap? Retrieved from https://www.thunderclap.it/about

Transparency and Open Government: Memorandum for the Heads of Executive Departments and Agencies, 74 Fed. Reg. 4685 (Jan. 21, 2009).

Vann, J.L. (2011). Institutional Dimensions of the Government's “Smart Buyer” Problem: Pillars, Carriers, and Organizational Structure in Federal Acquisition Management. (Unpublished doctoral dissertation). Virginia Polytechnic Institute and State University, Alexandria, Virginia. Retrieved from https://theses.lib.vt.edu/theses/available/etd-03102011182009/unrestricted/Vann_JL_D_2011.pdf

Wasserman, N. (2008). The Founder's Dilemma. Harvard Business Review. Retrieved from https://hbr.org/2008/02/the-founders-dilemma

United States Environmental Protection Agency (2014). FY 2014-2018 EPA Strategic Plan. Retrieved from http://www2.epa.gov/sites/production/files/201409/documents/epa_strategic_plan_fy14-18.pdf 
United States. Government Accountability Office. (2015, December 14). Environmental Protection Agency - Application of Publicity or Propaganda and Anti-Lobbying Provisions. (Publication No. B-326944.) Retrieved from http://www.gao.gov/assets/680/674163.pdf

United States. Cong. House. Committee on Oversight and Government Reform. Politicization of the Waters of the United States Rulemaking. $114^{\text {th }}$ Cong. 2016. Retrieved from https://oversight.house.gov/wp-content/uploads/2016/10/WOTUS-OGR-Report-final-forrelease-1814-Logo-1.pdf

Weerakkody, V., El-Haddadeh, R., Al-Sobhi, F., Shareef, M.A., and Dwivedi, Y.K. (2013). Examining the influence of intermediaries in facilitating e-government adoption: An empirical investigation. International Journal of Information Management, 33(5), 716-725.

Workman, S. (2015). The Dynamics of Bureaucracy in the U.S. Government: How Congress and Federal Agencies Process Information and Solve Problems. New York. Cambridge Univ. Press, pp. 6-106, 151-162. 
Table 1.

\begin{tabular}{|c|c|c|c|c|c|c|}
\hline & Texting & APR & EOBR & Accessibility & $\begin{array}{c}\text { Home } \\
\text { Mortgage }\end{array}$ & $\begin{array}{c}\text { Debt } \\
\text { Collection }\end{array}$ \\
\hline $\begin{array}{l}\text { Days Open } \\
\text { for Comment }\end{array}$ & 34 & 110 & 106 & 112 & 61 & 115 \\
\hline "Visits" & 3,729 & 24,441 & 8,855 & 12,631 & 12,665 & 12,629 \\
\hline "Visitors" & $\begin{array}{c}1,999 \\
\text { (53.6\% of } \\
\text { visits) }\end{array}$ & $\begin{array}{c}24,441 \\
\text { (79\% of } \\
\text { visits) }\end{array}$ & $\begin{array}{c}5,328 \\
\text { (60\% of } \\
\text { visits) }\end{array}$ & $\begin{array}{c}7,949 \\
\text { (64\% of } \\
\text { visits) }\end{array}$ & $\begin{array}{l}8,908 \\
(70 \% \text { of } \\
\text { visits ) }\end{array}$ & $\begin{array}{c}8,480 \\
\text { (67\% of visits) }\end{array}$ \\
\hline $\begin{array}{l}\text { Registered } \\
\text { Users }\end{array}$ & $\begin{array}{c}54 \\
\text { (2.7\% of } \\
\text { visitors) }\end{array}$ & $\begin{array}{c}1189 \\
\text { (6.2\% of } \\
\text { visitors) }\end{array}$ & $\begin{array}{c}121^{6} \\
\text { (2.3\% of } \\
\text { visitors) }\end{array}$ & $\begin{array}{c}68^{3} \\
\text { (.8\% of } \\
\text { visitors) }\end{array}$ & $\begin{array}{c}144 \\
\text { (1.6\% of } \\
\text { visitors) }\end{array}$ & $\begin{array}{c}377 \\
\text { (4.4\% of } \\
\text { visitors) }\end{array}$ \\
\hline Comments & $\begin{array}{c}18 \text { users } \\
\text { submitted } \\
32 \\
\text { comments }\end{array}$ & $\begin{array}{c}348 \text { users } \\
\text { submitted } \\
931 \\
\text { comments }\end{array}$ & $\begin{array}{c}68 \text { users } \\
\text { submitted } \\
235 \\
\text { comments }\end{array}$ & $\begin{array}{c}31 \text { users } \\
\text { submitted } \\
103 \\
\text { comments }\end{array}$ & $\begin{array}{c}67 \text { users } \\
\text { submitted } \\
236 \\
\text { comments }\end{array}$ & $\begin{array}{l}224 \text { users } \\
\text { submitted } \\
956 \\
\text { comments }\end{array}$ \\
\hline $\begin{array}{c}\text { Rulemaking } \\
\text { Experience }\end{array}$ & $\begin{array}{c}98 \% \\
\text { no/uncertain }\end{array}$ & $\begin{array}{c}94 \% \\
\text { no/uncertain }\end{array}$ & $\begin{array}{c}73 \% \\
\text { no/uncertain } 7\end{array}$ & $\begin{array}{c}64 \% \\
\text { no/uncertain }\end{array}$ & $\begin{array}{c}79 \% \\
\text { no/uncertain }\end{array}$ & $\begin{array}{c}83 \% \\
\text { no/uncertain }\end{array}$ \\
\hline
\end{tabular}

${ }^{6} 23$ of registered users did not complete survey

${ }^{7}$ Data was collected from 102 users. Four of those users had registered in previous rules.

${ }^{3} 16$ registered users did not complete survey

${ }^{4}$ Due to a technical error, only $13 \%$ of registrants were asked this question 